\title{
In search of an optimal acid-base indicator for examining surfactant micelles: Spectrophotometric studies and molecular dynamics simulations
}

\author{
Nikolay O. Mchedlov-Petrossyan, ${ }^{a *}$ Vladimir S. Farafonov, ${ }^{\text {a }}$ Tatyana A. Cheipesh, ${ }^{\text {a }}$ Sergey V. \\ Shekhovtsov, ${ }^{\text {a }}$ Dmitry A. Nerukh, ${ }^{\text {b }}$ Alexander V. Lebed ${ }^{\text {a }}$
}

${ }^{a}$ Department of Physical Chemistry, V. N. Karazin Kharkov National University, 61022, Kharkov, Ukraine

${ }^{\mathrm{b}}$ Systems Analytics Research Institute, Department of Mathematics, Aston University, Birmingham, B4 $7 E T, U K$

\section{A B S T R A C T}

We report on combined experimental and theoretical investigations of the water/micelle interface of cationic, anionic, zwitterionic, and non-ionic surfactants using a new hydrophobic acid-base indicator 2,6dinitro-4- $n$-dodecylphenol. The indices of the so-called apparent ionization constant, $\mathrm{p} K_{\mathrm{a}}^{\mathrm{app}}$, of the indicator fixed in the micellar pseudophase are determined by the spectrophotometric method. The data allows estimating the Stern layer's electrostatic potential of the ionic micelles $\Psi$. Molecular Dynamics modeling was used to locate the dye molecule and, in particular, its ionizing group $\mathrm{OH} \rightarrow \mathrm{O}^{-}$within the micelles of the studied surfactants. The comparison of the $\Psi$ values estimated using 2,6-dinitro-4- $n$ dodecylphenol with both our computer simulation and literature experimental results reveals obstacles in monitoring electrical interfacial potentials. In particular, the $\Psi$ values of the surfactant micelles with alkylammonium groups determined via 2,6-dinitro-4- $n$-dodecylphenol are overestimated. The reason is specific interactions of the indicator anion with the surfactant head groups. For anionic surfactants, however, this indicator is quite suitable, which is confirmed by the location of $\mathrm{HA}$ and $\mathrm{A}^{-}$equilibrium forms in the pseudophase.

\section{Key words}

Surfactant, micelle, acid-base indicator, apparent ionization constant, surface potential, molecular dynamics, Stern layer 
Highlights

2,6-Dinitro-4- $n$-dodecylphenol is a useful indicator for examining micelles

The indicator's long tail ensures similar positioning of the molecule and its anion

The interaction of the surfactant's alkylammonium groups with the indicator's nitro groups is revealed

2,6-Dinitro-4- $n$-dodecylphenol is more appropriate for anionic micelles 


\section{Introduction}

Acid-base indicators are universal tools for examining versatile colloidal aggregates and interfaces [1-3]. They are widely used for studying surfactant micelles [1-3], drops of microemulsions [2, 3], phospholipid bilayers [1], gelatin layers [4], polymers [5], etc. Not only color transitions, but also light emission of fluorescent indicators is often used for monitoring properties of micelles [6, 7]. Among other aims, the estimation of the electrostatic surface potential of micelles and related aggregates is of special interest. Meanwhile, the information derived using the acid-base indicators depends fundamentally on the locus of these molecular probes within the micellar pseudophase. Nowadays, this issue can be elucidated using the molecular dynamics modeling of a micelle plus indicator complex immersed into aqueous environment. This, in turn, allows validating different indicators from the viewpoint of their usefulness for the declared aim. The present paper demonstrates a step in this direction.

For the ionization of an indicator acid, HA, completely fixed in a micellar pseudophase, the so-called apparent $\mathrm{p} K_{\mathrm{a}}^{\mathrm{app}}$ value can be obtained using the spectrophotometric procedure, Eq. (1).

$$
\mathrm{p} K_{\mathrm{a}}^{\mathrm{app}}=\mathrm{pH}+\log \frac{[\mathrm{HA}]}{\left[\mathrm{A}^{-}\right]}
$$

The concentration ratio indicator : micelle in the solution should be around unity. Normally, the bulk $\mathrm{pH}$ value is determined potentiometrically with a glass electrode in a cell with liquid junction. The brackets denote the equilibrium concentrations of the corresponding forms. The $\mathrm{p} K_{\mathrm{a}}^{\mathrm{app}}$ value can be represented as shown in Eq. (2), which is sometimes called the Hartley-Mukherjee-Fromherz-Funasaki (HMFF) equation [8-13].

$$
\mathrm{p} K_{\mathrm{a}}^{\mathrm{app}}=\mathrm{p} K_{\mathrm{a}}^{\mathrm{w}}+\log \frac{\gamma_{\mathrm{A}^{-}}}{\gamma_{\mathrm{HA}}}-\frac{\Psi F}{R T \ln 10}=\mathrm{p} K_{\mathrm{a}}^{\mathrm{i}}-\frac{\Psi F}{R T \ln 10}
$$


Here $K_{\mathrm{a}}^{\mathrm{w}}$ is the thermodynamic ionization constant in water, $K_{\mathrm{a}}^{\mathrm{i}}$ is called 'intrinsic' constant, $\gamma_{\mathrm{A}^{-}}$and $\gamma_{\mathrm{HA}}$ are the activity coefficients of the transfer of the indicator forms from water to the micellar pseudophase, $\Psi$ stands for the electrostatic potential of the micellar surface of an ionic surfactant, that is the Stern layer, $F, R$, and $T$ have their usual meanings. The spectroscopic method gives the ratio of the equilibrium concentrations of $\mathrm{HA}$ and $\mathrm{A}^{-}$forms. Contrary to the $\mathrm{p} K_{\mathrm{a}}^{\mathrm{app}}$ value, direct determination of $\mathrm{p} K_{\mathrm{a}}^{\mathrm{i}}$ is challenging, however, some indirect methods are developed [1-3, 9, 11-15]. Clearly, from the $\mathrm{p} K_{\mathrm{a}}^{\mathrm{app}}$ and $\mathrm{p} K_{\mathrm{a}}^{\mathrm{i}}$ values, it is possible to estimate the $\Psi$ value for the given ionic micelle, Eq. (3).

$$
\Psi=\frac{R T \ln 10}{F}\left(\mathrm{p} K_{\mathrm{a}}^{\mathrm{i}}-\mathrm{p} K_{\mathrm{a}}^{\mathrm{app}}\right)
$$

This approach can also be used for droplets of microemulsions [3], phospholipid liposomes [16, 17], monolayers $[10,18]$, etc; see ref. [1-3, 14, 15, 19-22] for details.

However, using different indicators for these measurements provides different $\Psi$ values for the same system [2, 3, 23]. Therefore, some conditions should be established to minimize the variability. Such 'best' indicators should be firmly fixed in the pseudophase and its ionizing group should be located in the Stern layer. Though some disturbances of the microenvironment by the indicator molecule are inevitable, they should be as small as possible. Hence, the size of the molecule should be not too large. Finally, as the $K_{\mathrm{a}}^{\mathrm{i}}$ value is usually modeled by the ionization constant either in nonionic micelles or in water-organic mixtures, the location of the acidic and basic forms of the indicator in the micellar pseudophase should be similar. After the publications by Fromherz et al. [10, 11], the coumarin indicators with long hydrophobic hydrocarbon tails were often used for these purposes $[15,16]$. Also, the solvatochromic betaine dye, the so-called Reichardt's dye, which is also an acid-base indicator, was utilized [2, 14]. Some other hydrophobic, especially long-tailed indicators were examined [20]. A hydrophobic dye $N, N^{\prime}$-di- $n$ octadecylrhodamine was also proposed for $\Psi$ estimation $[2,21]$. Though the molecule of this dye is rather bulky, and the ionization of the $\mathrm{COOH}$ group displays only a small spectral effect, the $N, N^{\prime}$-di- $n$ octadecylrhodamine was proposed because the change of the $\mathrm{p} K_{\mathrm{a}}$ values of rhodamines in going from 
water to water-organic mixtures [24] and the micelles of nonionic surfactants [2, 21] is small. This is because the acid-base couple is of cation/zwitterion type. Therefore, it can minimize the errors in modeling the $\mathrm{p} K_{\mathrm{a}}^{\mathrm{i}}$ values in ionic micelles by those in nonionic ones.

NMR spectroscopy was often used for revealing the location of the indicators within the micellar pseudophases $[20,25,26]$, together with theoretical approaches applied to the same or similar systems $[27-31]$.

We performed several Molecular Dynamics (MD) simulations of Reichardt's betaines in their cationic and zwitterionic forms in micelles of various surfactants [32-34]. In a special paper [22], we applied MD modeling to the first acid-base indicator used in 1940 by Hartley and Roe for estimating the electric potential of micelles [8] and discovered some peculiarities in location of this dye molecule and its anion in cationic and anionic micelles.

In the present paper, we propose a new indicator, 2,6-dinitro-4- $n$-dodecylphenol (DDP), as a possible suitable tool for examining the micellar surfaces. The rationale is as follows. (i) The dodecyl chain ensures the fixation of the indicator in the micelles of surfactants of any types. (ii) The aromatic moiety is not very large. (iii) Based on our previous studies [22, 32-34], the HA and $\mathrm{A}^{-}$forms are expected to have similar orientation in the interfacial micellar layer. (iv) The $\mathrm{p} K_{\mathrm{a}}$ values of nitrophenols undergo rather small changes in going from water to water-organic mixed solvents [35-37]. Therefore, we expected that the variations of the $\mathrm{p} K_{\mathrm{a}}^{\mathrm{i}}$ value in going from nonionic to ionic micelles will be caused mainly by the $\Psi$ values of the latter.

Various alkyl derivatives of nitro- and dinitrophenols were often used in biophysical research [3839]. Hence, the indicator considered in the present study may be useful in examining biological objects.

This indicator was synthesized and its $\mathrm{p} K_{\mathrm{a}}^{\text {app }}$ value was determined in the micellar solutions of $N$ cetylpyridinium chloride (CPC), cetyltrimethylammonium bromide (CTAB), cetyldimethylammonium propanesulfonate (CDAPS), Triton X 100 (TX 100), and sodium $n$-dodecylsulfate (SDS). MD modeling was carried out for the HA molecule and the $\mathrm{A}^{-}$anion in micelles of ionic surfactants. The molecular structures of the indicator and the surfactants are shown in Scheme 1. 
We show that this indicator can be used for reliably measuring the $\Psi$ values of anionic surfactant micelles, while for surfactants possessing alkylammonium head groups the $\Psi$ values obtained this way are biased. We suggest a molecular explanation for this effect.

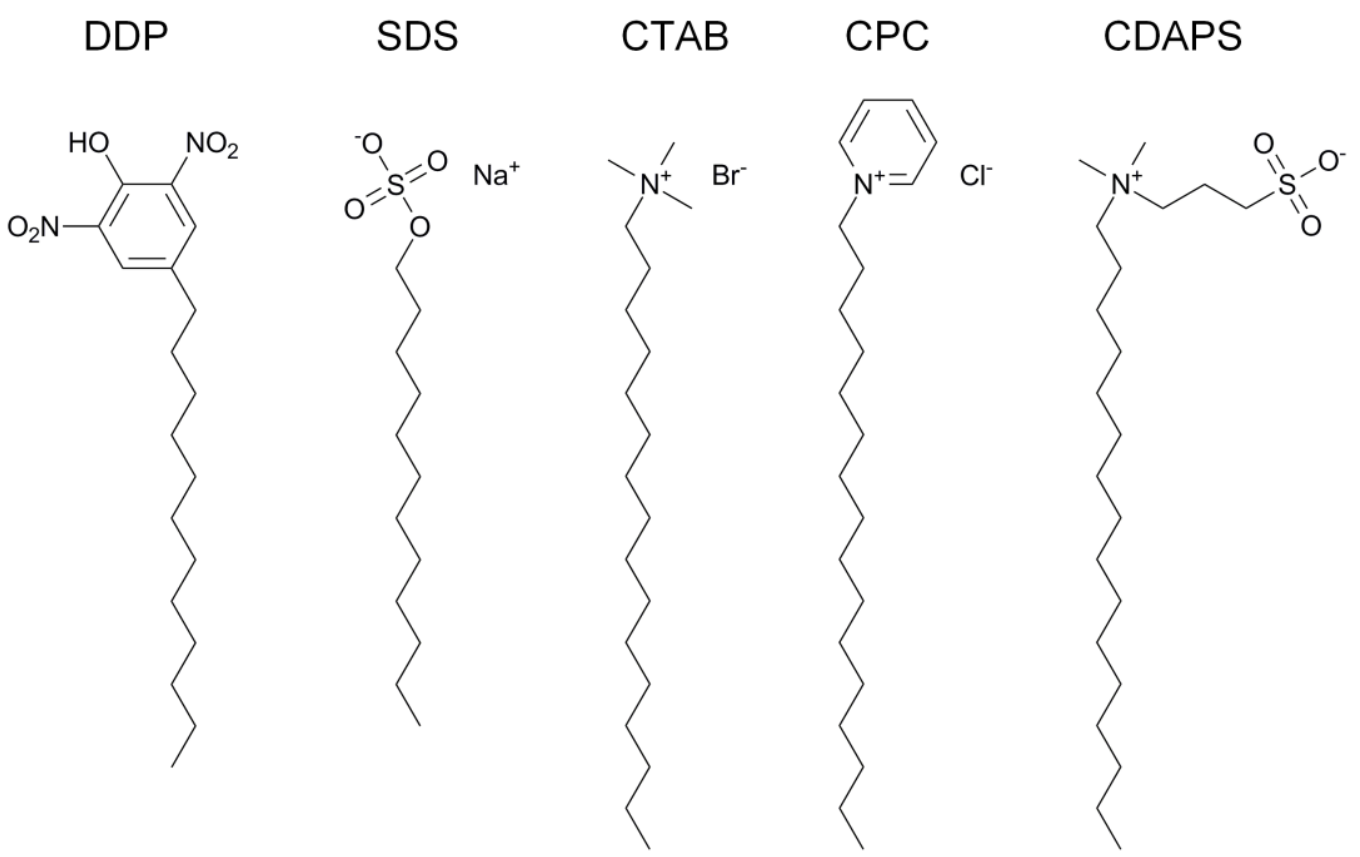

\section{TX 100}

Scheme 1. Molecular structures of the studied dye (DDP) and surfactants.

\section{Materials and methods}

\subsection{Chemicals}

Hydrochloric, hydrobromic, sulfuric, and acetic acids, sodium and potassium chlorides were of analytical grade. The aqueous solution of $\mathrm{NaOH}$ was prepared from a saturated solution using $\mathrm{CO}_{2}$-free water and it was kept protected from the atmosphere. Standard buffers with pH 1.68 (oxalate); 4.01 (ophthalate); 6.86 (phosphate); and 9.18 (borate) at $25{ }^{\circ} \mathrm{C}$ were used for $\mathrm{pH}$ standardization. $\mathrm{CPC}\left(\times 1 \mathrm{H}_{2} \mathrm{O}\right.$, Merck, 99 \%), CTAB (Sigma, 99 \%), CDAPS (Fluka, >99\%), SDS, (Vekton, Russia), TX 100 (Sigma) were used as received.

\subsection{Synthesis of 2,6-dinitro-4-n-dodecylphenol and its sodium salt}

The sample of 4- $n$-dodecylphenol was prepared as described in the literature $[40,41]$. To the solution of $0.262 \mathrm{~g}$ of $4-n$-dodecylphenol in $1.5 \mathrm{~mL}$ of glacial acetic acid $0.3 \mathrm{~g} 99 \%$ nitric acid was added under 
stirring. After $1 \mathrm{~h}$, the reaction mass was poured on the mixture of $5 \mathrm{~g}$ ice and $1 \mathrm{ml}$ of $10 \%$ aqueous ammonia. The deposited precipitate was extracted with several $2 \mathrm{~mL}$-portions of dichloromethane. The extract was evaporated in vacuum, and thus obtained substance was three times re-crystallized from ethanol containing an excess of aqueous ammonia. The orange ammonium salt of 2,6-dinitro-4-ndodecylphenol was heated for $1.5 \mathrm{~h}$ at $160{ }^{\circ} \mathrm{C}$ and $60 \mathrm{~mm} \mathrm{Hg}$. After the quantitative decomposition of the salt, 2,6-dinitro-4- $n$-dodecylphenol was obtained; m.p. $60.0-60.5{ }^{\circ} \mathrm{C}$. The compound was diluted on heating in $10 \mathrm{~mL}$ of ethanol containing $0.04 \mathrm{~g}$ of $\mathrm{NaOH}$. After cooling, the red crystals of the sodium 2,6dinitro-4- $n$-dodecylphenolate were deposited. The product was twice re-crystallized from $50 \%$ aqueous ethanol. The yield was $0.13 \mathrm{~g}$. ${ }^{1} \mathrm{H}$ NMR of 2,6-dinitro-4- $n$-dodecylphenol in $\mathrm{CDCl}_{3}:{ }^{1} \mathrm{H} \mathrm{NMR}\left(\mathrm{CDCl}_{3}\right), \delta$ ppm): $11.26(1 \mathrm{H}, \mathrm{s}), 8.11(2 \mathrm{H}, \mathrm{s}), 2.66(2 \mathrm{H}, \mathrm{t}, J=7.9 \mathrm{~Hz}), 1.63(2 \mathrm{H}, \mathrm{m}), 1.36-1.18(18 \mathrm{H}, \mathrm{m}), 0.86(3$, $\mathrm{t}, J=6.1 \mathrm{~Hz})$.

\subsection{Preparation of indicator + surfactant systems}

Weight amounts of the indicator and the surfactant were pounded and transferred into a 25 or $50 \mathrm{~mL}$ volumetric flask. A small amount of water was added and the mixture was heated on a water bath. After eight-minute sonication it was placed in a thermostat. After making up to the required volume and careful mixing, the working solutions were prepared by diluting an aliquot ( 1 or $2 \mathrm{~mL}$ ) of the initial solution with a buffer mixture and a salt solution and topping up to $10 \mathrm{~mL}$. The indicator concentration in the working solutions in different surfactant systems was $(3$ to 8$) \times 10^{-5} \mathrm{M} .{ }^{1}$ The preparation of the solutions, the $\mathrm{pH}$ and spectra measurements have been carried out at $25^{\circ} \mathrm{C}$.

\subsection{Spectrophotometric determination of the apparent ionization constants}

The absorption spectra were measured with the Hitachi U-2000 spectrophotometer against solvent blanks, at $25.0 \pm 0.1{ }^{\circ} \mathrm{C}$. The $\mathrm{pH}$ values were determined using the $\mathrm{R} 37-01$ potentiometer and $\mathrm{pH}-121$ pH-meter (Russia) with an ESL-43-07 glass electrode (Gomel, Belarus) in a cell with liquid junction (3 $\left.\mathrm{M}^{*} \mathrm{KCl}\right)$. An $\mathrm{Ag} \mid \mathrm{AgCl}$ electrode was used as a reference electrode. The glass electrode was calibrated with standard buffer solutions ( $\mathrm{pH} 1.68,4.01,6.86$, and 9.18 at $25^{\circ} \mathrm{C}$ ). The particle size distribution and

\footnotetext{
${ }^{1}$ Hereafter, $1 \mathrm{M}=1 \mathrm{~mol} \mathrm{dm}{ }^{-3}$.
} 
the zeta-potentials were determined by dynamic light scattering (DLS) using Zetasizer Nano ZS Malvern Instruments.

\subsection{Experimental procedure}

The concentration of CTAB in the working solutions was $0.003 \mathrm{M}$, the $\mathrm{pH}$ values were adjusted using either $\mathrm{HBr}$, with $\mathrm{NaBr}$ addition (ionic strength $0.1 \mathrm{M}$ ) or $\mathrm{HCl}$, with $\mathrm{KCl}$ addition (ionic strength 4.00); the spectra of $\mathrm{HA}$ and $\mathrm{A}^{-}$were measured in $0.66-1.0 \mathrm{M} \mathrm{HBr}$ and $0.09 \mathrm{M} \mathrm{HCl}$ solution and in borate and phosphate buffer solutions, at $\mathrm{pH} 9.2$ and 6.9, respectively. The concentration of other surfactants in the working solutions was $0.01 \mathrm{M}$. In CPC and CDAPS solutions, the $\mathrm{pH}$ values were adjusted using $\mathrm{HCl}$, the ionic strength $0.10 \mathrm{M}$ was maintained by adding $\mathrm{NaCl}$. The spectra of $\mathrm{HA}$ and $\mathrm{A}^{-}$were measured in 4.5 $\mathrm{M} \mathrm{H}_{2} \mathrm{SO}_{4}$ and $1 \mathrm{M} \mathrm{HCl}$, respectively. In the solutions of TX 100 , the acetate buffers $\left(\mathrm{CH}_{3} \mathrm{COOH}+\mathrm{NaOH}\right.$ mixtures) were used, whereas in the SDS solutions, besides acetate, several phosphate buffers were also used. The ionic strength of $0.10 \mathrm{M}$ was maintained by $\mathrm{NaCl}$ additions. In these two surfactant systems, the spectra of the HA form were measured in $0.05 \mathrm{M} \mathrm{HCl}$ solutions. The spectra of $\mathrm{A}^{-}$were measured in borate and phosphate buffer solutions.

The ratio of the equilibrium concentrations of the acidic and basic forms was determined spectrophotometrically using the standard procedure. For each system, around 8 solutions with different $\mathrm{pH}$ values were normally used. As analytical positions, ca. 20 wavelengths with $1 \mathrm{~nm}$-interval around $\lambda_{\text {max }}$ of $\mathrm{A}^{-}$were used.

\subsection{Simulation protocol}

The computational part of the work was done using GROMACS 5 software package [42] The simulations were carried at standard conditions (the temperature of $298 \mathrm{~K}$; the pressure of $1 \mathrm{bar}$ ), which were maintained by the Berendsen algorithms with the thermostat time constant of 1 ps and the barostat time constant of $1.5 \mathrm{ps}$. 3D periodic boundary conditions were imposed. The time step equaled 2 fs for SDS or 1.6 fs for CTAB and CDAPS. The constraints were put on all bonds, the particle mesh Ewald method was used for electrostatics, and van der Waals interactions were cut at $1 \mathrm{~nm}$. 
For each system, the initial configuration was a water box containing the micelle with the dye molecule placed inside. The length of the box and the number of monomers in the micelle was equal to 8 $\mathrm{nm}$ and 60 for SDS or $9.7 \mathrm{~nm}$ and 80 for CTAB and CDAPS, respectively. 60 and 80 were the aggregation numbers of the first two surfactants [43], while for CDAPS, the value equal to CTAB was taken to facilitate the comparison of computed characteristics between CTAB and CDAPS. As we have revealed for Reichardt's dye in CTAB micelles [34], the aggregation number value does not considerably affect the computed state of the indicator molecule. Three initial configurations were prepared for each particular system. They were qualitatively similar and differed in the location of the dye molecule inside the micelle only. The initial configurations were subject to a $10 \mathrm{~ns}$ equilibration after which $30 \mathrm{~ns}$ productive runs were performed. During the $10 \mathrm{~ns}$ period the dye molecule relocated from the micelle interior to the micelle surface, and the rest of the run resided there. Reaching equilibrium was estimated by computing orientation of the molecule and hydration of the hydroxyl $\mathrm{O}$ atom (as described in sections $3.4,3.5)$ by $0-5 \mathrm{~ns}, 5-10 \mathrm{~ns}, 10-15 \mathrm{~ns}$, and $10-40 \mathrm{~ns}$ intervals and comparing them. The $5-10 \mathrm{~ns}, 10-15$ ns, and 10-40 ns averages were generally close to one another while $0-5$ ns usually outstood indicating $10 \mathrm{~ns}$ is enough for equilibration of such systems. For each system the characteristics computed for each of the three runs, were averaged.

The simulations were performed using the well known OPLS-AA force field [44]. The models for SDS and CTAB were taken from our previous works [45,46], while the one for CDAPS was prepared as follows. In the CTAB potential model, one methyl group was replaced with the ethyl group, represented the standard OPLS-AA parameters. Then, the $\mathrm{CH}_{2}-\mathrm{SO}_{3}{ }^{-}$group extracted from our potential model for sodium dodecyl sulfonate [22] was attached to the ethyl group.

The dye was parameterized in accordance with the standard OPLS-AA methodology in order to keep the mutual compatibility of all used potential models. Even though the force field contained the values of the atomic point charges for the hydroxyl, nitro, and methyl groups, bonded to a benzene ring, we decided to recalculate these charges for the DDP molecule because the built-in charges were obtained for singlesubstituted benzene derivatives, while in the case of DDP the interactions between the substituents leads to redistribution of the electronic density. At the first stage, quantum-chemical geometry optimization of 
the molecule at the RHF level of theory using the 6-31G(d) basis set was performed. Then, fitting the distribution of the electrostatic potential around the molecule with a system of atom-centered point charges using the CHELPG algorithm [47] was done.

We used the RED server [48] linked to Gaussian 09.E to perform the procedure [49]. The point charges were computed for the 2,6-dinitro-4-methylphenol molecule, while for the rest of the hydrocarbon tail they were taken from the force field. This is justified because the inductive effect of the benzene ring on the hydrocarbon chain quickly diminishes.

We also prepared the potential models for two other dyes 2,6-dinitro-4-pentylphenol (PDP) and 2nitro-4-nonylphenol (NNP). For deriving the potential model of the latter compound, quantum-chemical computations were performed for the 2-nitro-4-methylphenol molecule.

The counter-ion for the anionic forms was $\mathrm{Na}^{+}$, and water was represented by the SPC model.

\section{Results and Discussion}

\subsection{Experimental determination of ionization constants in micelles}

The absorption spectra of 2,6-dinitro-4- $n$-dodecylphenol in micellar media at different $\mathrm{pH}$ values are presented in Figures $1-3$. The maximal molar absorptivities of the HA molecule and the $\mathrm{A}^{-}$ion in various micellar systems are around $4.9 \times 10^{3} \mathrm{M}^{-1} \mathrm{~cm}^{-1}$ and $9.1 \times 10^{3} \mathrm{M}^{-1} \mathrm{~cm}^{-1}$, respectively. The isosbestic point is unambiguous, except the CDAPS and CTAB $+4.0 \mathrm{M} \mathrm{KCl}$ systems. In CDAPS, the working solutions were stable only for $10 \mathrm{~min}$, after which some sediment was deposited. They were restored via slight heating.

Taking into account that the aggregation number of the surfactants in all systems is of the order of $10^{2}$, the dye : micelle ratio was around unity or somewhat higher. The DLS study demonstrates that the micellar size with and without the indicator are approximately equal. 

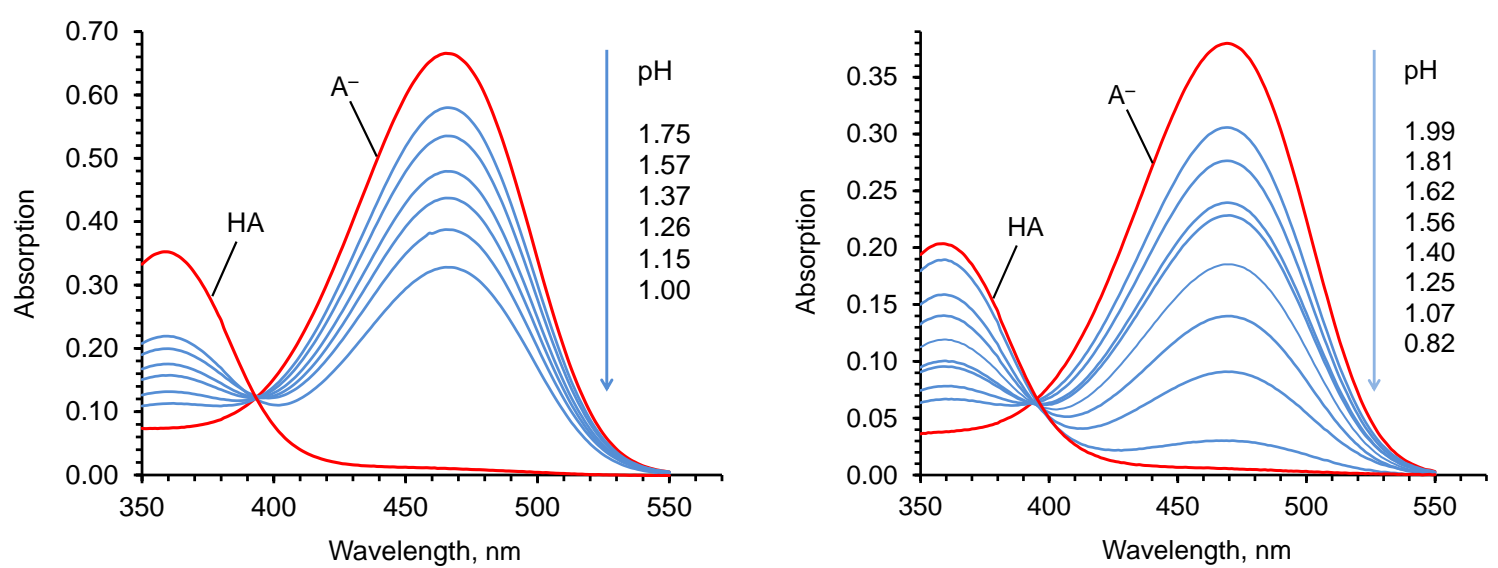

Fig. 1 Absorption spectra of 2,6-dinitro-4- $n$-dodecylphenol in $0.01 \mathrm{M} \mathrm{CPC}$ solutions, $0.1 \mathrm{M} \mathrm{NaCl}$ (a) and 0.003 M CTAB solutions, $0.1 \mathrm{M} \mathrm{NaBr}(\mathrm{b})$.
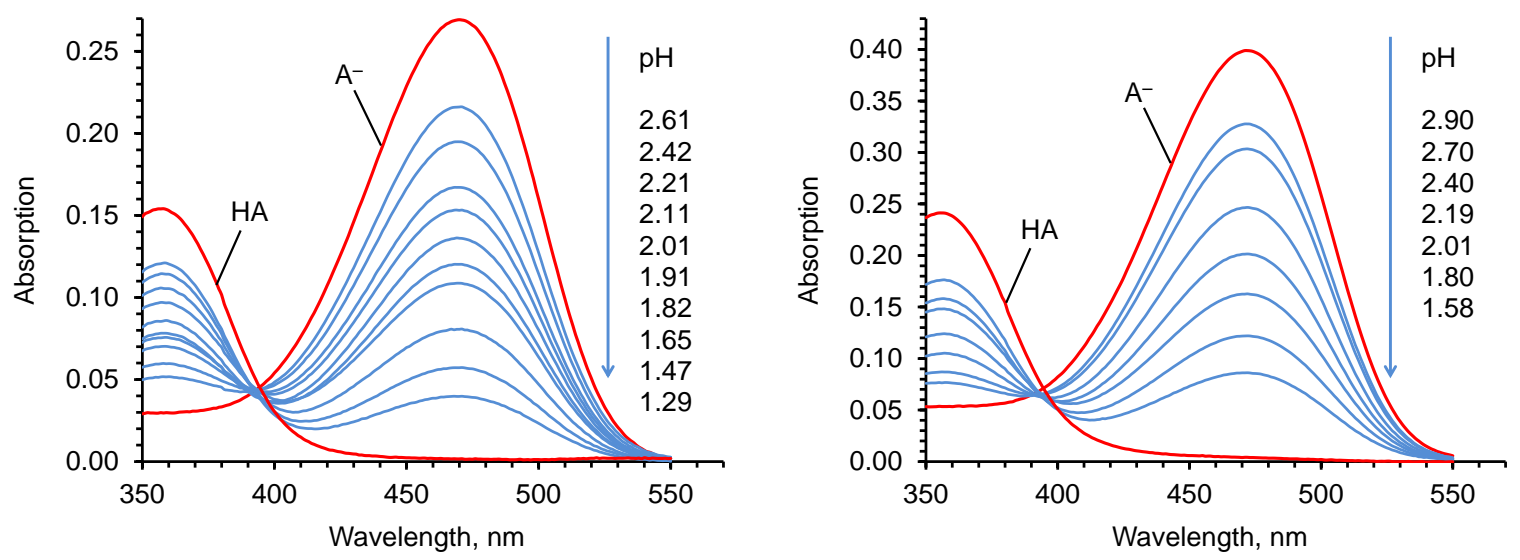

Fig. 2 Absorption spectra of 2,6-dinitro-4- $n$-dodecylphenol in 0.01 M CDAPS solutions, 0.1 M $\mathrm{NaCl}$ (a) and 0.003 M CTAB solutions, 4.0 M KCl (b).
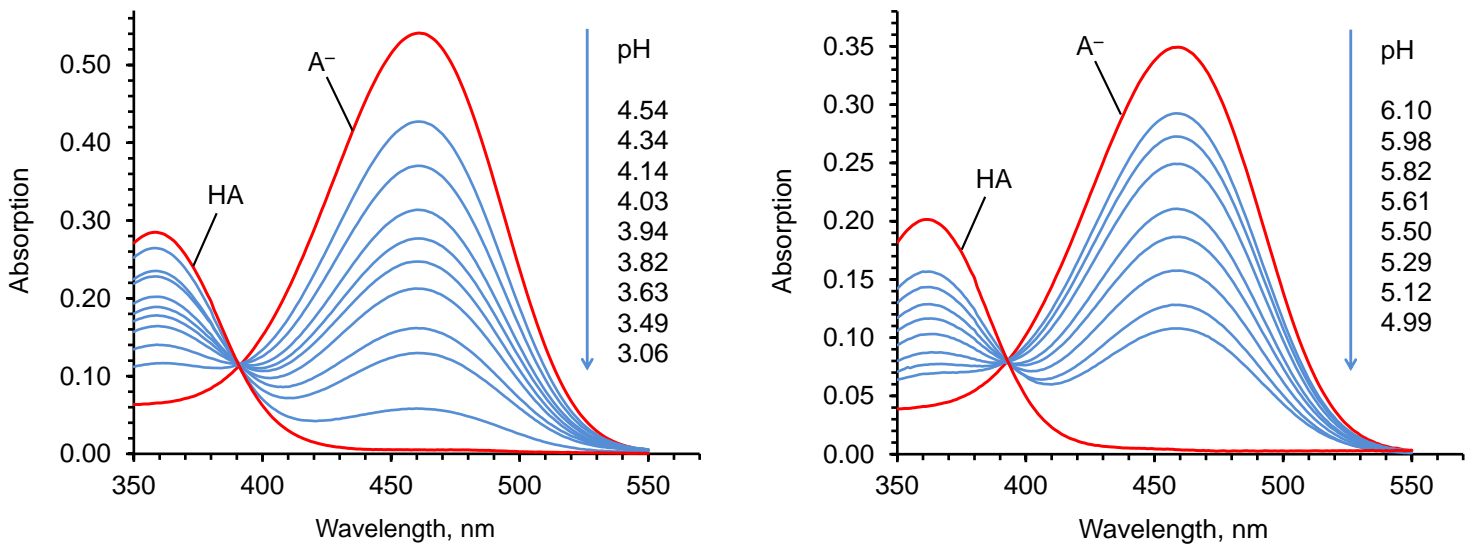

Fig. 3 Absorption spectra of 2,6-dinitro-4- $n$-dodecylphenol in $0.01 \mathrm{M}$ TX 100 solution, $0.1 \mathrm{M}$ $\mathrm{NaCl}$ (a) and 0.01 M SDS solution, $0.1 \mathrm{NaCl}(\mathrm{b})$. 
The dependences of the ionization degree of the indicator on $\mathrm{pH}$ are shown in Fig. 4. The solid lines correspond to the ionization degrees calculated using the $\mathrm{p} K_{\mathrm{a}}^{\mathrm{app}}$ values.

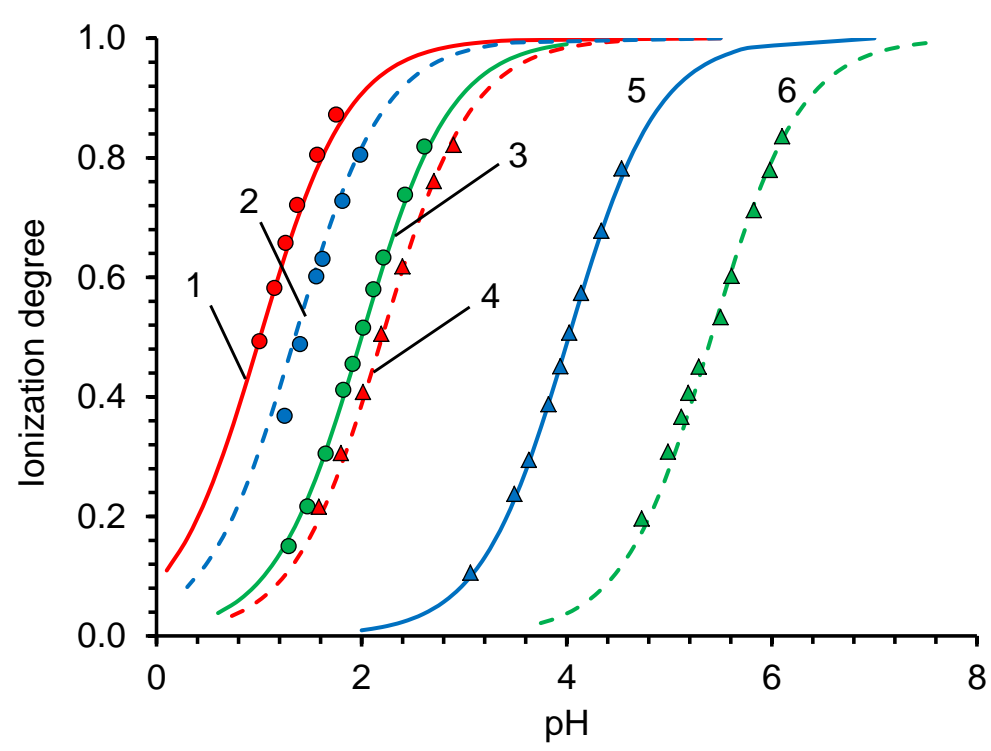

Fig. 4 Dependence of ionization degree of 2,6-dinitro-4- $n$-dodecylphenol fixed in micelles vs pH of the bulk (aqueous) phase in micellar solutions of CPC (1); CTAB (2, 4); CDAPS (3); TX 100 (5); SDS (6). Surfactant concentrations: $0.01 \mathrm{M}$ (CPC, CDAPS, TX 100, SDS) and $0.003 \mathrm{M}$ (CTAB); ionic strength of the bulk phase for (2) and (4): $0.1 \mathrm{M} \mathrm{NaBr}$ and 4.0 M KCl, respectively; in all other cases: $0.10 \mathrm{M}$ $(\mathrm{NaCl}) ; 25^{\circ} \mathrm{C}$.

The $\mathrm{p} K_{\mathrm{a}}^{\mathrm{app}}$ and $\lambda_{\max }$ values are collected in Table 1 . The data qualitatively agree with the data published for nitrophenols in micellar media $[37,50,51]$. The $\mathrm{p} K_{\mathrm{a}}^{\text {app }}$ value in CPC micelles is lower than in CTAB (Table 1). This is in line with the data for a number of nitrophenols [50] and other dyes [2, 3]. Also, the $\mathrm{p} K_{\mathrm{a}}^{\mathrm{app}}$ of a given indicator is as a rule lower in a cationic micelle with $\mathrm{Cl}^{-}$counterion as compared with that with $\mathrm{Br}^{-}$, everything else being equal [2, 3]. The results for 2,6-dinitro-4dodecylphenol obtained in the present study should be compared with those published in our previous paper devoted to nitrophenols, including 2,6-dinitrophenol in cationic and zwitterionic micelles [52].

Table 1. Indices of apparent ionization constants of 2,6-dinitro-4-dodecylphenol and related parameters ${ }^{\text {a }}$

\begin{tabular}{|l|c|c|c|c|c|c|}
\hline Surfactant, conc. & $\begin{array}{c}\text { Salt } \\
\text { background, }\end{array}$ & $\lambda_{\max }(\mathrm{HA}), \mathrm{nm}$ & $\lambda_{\max }\left(\mathrm{A}^{-}\right), \mathrm{nm}$ & $\mathrm{p} K_{\mathrm{a}}^{\text {app }}$ & $\Delta \mathrm{p} K_{a}^{a p p} \mathrm{~d}$ & $\Psi, \mathrm{mV}$ \\
\hline
\end{tabular}




\begin{tabular}{|l|c|c|c|c|c|c|}
\hline & $\mathrm{M}$ & & & & & - \\
\hline None $^{\mathrm{b}}$ & 0 & 345 & 430 & $3.71^{\mathrm{c}}$ & - & -82 \\
\hline SDS, 0.01 M & 0.1 & 362 & 459 & $5.41 \pm 0.02$ & +1.3 & \\
\hline TX 100, 0.01 M & 0.1 & 358 & 462 & $4.02 \pm 0.01$ & -0.1 & 0 \\
\hline CDAPS, 0.01 M & 0.1 & 358 & 469 & $2.00 \pm 0.02$ & -2.1 & +120 \\
\hline CTAB, 0.003 M & $4.00(\mathrm{KCl})$ & 356 & 472 & $2.20 \pm 0.02$ & -1.9 & +108 \\
\hline CTAB, 0.003 M & $0.1\left(\mathrm{Br}^{-}\right)$ & 359 & 469 & $1.35 \pm 0.05$ & -2.8 & +158 \\
\hline CPC, 0.01 M & 0.1 & 359 & 465 & $1.01 \pm 0.02$ & -3.1 & +178 \\
\hline
\end{tabular}

Note. ${ }^{\text {a }}$ Ionic strength 0.10 (buffer $+\mathrm{NaCl}$ ), if not otherwise specified; ${ }^{\mathrm{b}}$ data for 2,6-dinitrophenol, ref. [52]; ${ }^{\mathrm{c}}$ thermodynamic value for 2,6-dinitrophenol, $\mathrm{p} K_{\mathrm{a}}^{\mathrm{w}}$; in ref. [35], $\mathrm{p} K_{\mathrm{a}}^{\mathrm{w}}=3.70 .{ }^{\mathrm{d}}$ For $\Delta \mathrm{p} K_{a}^{a p p}$ calculation, a value of $\mathrm{p}_{\mathrm{a}}^{\mathrm{w}}=4.1$ was used, see the text.

It is also interesting to compare the $\lambda_{\max }$ values with those for 2,6-dinitrophenol [52]. In CDAPS and CTAB micelles, $\lambda_{\max }\left(\mathrm{A}^{-}\right)$for 2,6-dinitrophenol is 450 and $455 \mathrm{~nm}$, respectively. These are higher than in water $(430 \mathrm{~nm})$ but lower than those for the hydrophobic analogue in the same micelles, which are around $470 \mathrm{~nm}$ (Table 1). This gives evidence for deeper penetration into the micellar pseudophase of the 2,6dinitro-4-dodecylphenolate as compared with the less hydrophobic analog.

The $\mathrm{p} K_{\mathrm{a}}^{\mathrm{app}}$ values of the hydrophilic dinitrophenol are always higher than for the hydrophobic dye in the above micelles. In CDAPS, at $0.05 \mathrm{M} \mathrm{Cl}^{-}, \mathrm{p} K_{\mathrm{a}}^{\mathrm{app}}=2.53 \pm 0.02$ at the maximal surfactant concentration $(0.005 \mathrm{M})$ [52], whereas the extrapolation to complete binding of $\mathrm{HA}$ and $\mathrm{A}^{-}$by the micelles results in $\mathrm{p} K_{\mathrm{a}}^{\mathrm{app}}=2.76 \pm 0.02$ [52]. For 2,6-dinitro-4-dodecylphenol in CDAPS micelles, $\mathrm{p} K_{\mathrm{a}}^{\text {app }}$ $=2.00 \pm 0.02$ (Table 1). In 0.01 M CTAB solution at $4.00(\mathrm{KCl}), \mathrm{p} K_{\mathrm{a}}^{\mathrm{app}}$ of 2,6-dinitrophenol is $2.51 \pm 0.02$ [52], which is also substantially higher than $\mathrm{p} K_{\mathrm{a}}^{\mathrm{app}}=2.20 \pm 0.02$ of the hydrophobic indicator (Table 1). Finally, in $\mathrm{CTAB}$ at $0.05 \mathrm{M} \mathrm{Br}^{-}$, the $\mathrm{pK}_{\mathrm{a}}^{\mathrm{app}}$ value of 2,6-dinitrophenol is $1.31 \pm 0.01$ [52]. The extrapolation to $0.1 \mathrm{M} \mathrm{Br}^{-}$using the well-known approaches [2] leads to a value of 1.5-1.6, which is also 
higher than $1.35 \pm 0.05$ in Table 1. Concluding, in all cases the $\mathrm{p} K_{\mathrm{a}}^{\mathrm{app}}$ of 2,6-dinitro-4-dodecylphenol in cationic and zwitterionic micelles is lower than for the indicator without the $\mathrm{C}_{12} \mathrm{H}_{25}$ tail. A possible explanation is that the hydrophobic dye penetrates deeper into the micellar pseudophase in accordance with the $\lambda_{\max }$ values (see above).

Another problem is that the thermodynamic $K_{\mathrm{a}}^{\mathrm{w}}$ value of 2,6-dinitro-4-dodecylphenol in water is unavailable experimentally. For 2,6-dinitrophenol $\mathrm{p} K_{\mathrm{a}}^{\mathrm{w}}=3.71$. Using the Hammett's $\sigma=0.15$ and $\rho=$ 2.1 constants for 4-alkyl radical and phenol in water the $\mathrm{p} K_{\mathrm{a}}^{\mathrm{w}}=4.02$ value can be predicted. However, the nitro groups in 2- and 6-positions can influence the electronic effect of the alkyl chain. For 4-methyl2,6-dinitrophenol, an experimental value of 4.35 is available [53], whereas for 4-isobutyl-, 4-isoamyl-, and 4-isooctyl- derivatives of 2,6-dinitrophenol, the values of 4.3, 4.1, and 4.1, respectively were determined [38]. In any case, the difference between the $\mathrm{p} K_{\mathrm{a}}^{\mathrm{app}}$ in $\mathrm{TX} 100$ and $\mathrm{p} K_{\mathrm{a}}^{\mathrm{w}}$ is small, thus confirming the choice of the indicator.

\subsection{Micellar effects and estimation the electrostatic surface potential}

The values of $\Delta \mathrm{p} K_{\mathrm{a}}^{\mathrm{app}}=\mathrm{p} K_{\mathrm{a}}^{\mathrm{app}}-\mathrm{p} K_{\mathrm{a}}^{\mathrm{w}}$ calculated using the $\mathrm{p} K_{\mathrm{a}}^{\mathrm{w}}$ value of 4.1 are shown in Table 1 . The sign of the effects is predictable: increasing $\mathrm{p} K_{\mathrm{a}}^{\mathrm{app}}$ in SDS micelles and decreasing in cationic ones. An important detail is a substantial $\mathrm{p} K_{\mathrm{a}}^{\mathrm{app}}$ decrease in the zwitterionic micelles and in the case of a cationic surfactant under the condition of strong shielding of the micellar surface charge via $4 \mathrm{M} \mathrm{KCl}$.

The calculation of the $\Psi$ values using Eq. (3) was done following one of the most recognized procedures. Namely, the $\mathrm{p} K_{\mathrm{a}}^{\mathrm{i}}$ value in ionic (including zwitterionic) micelles was equated to the $\mathrm{p} K_{\mathrm{a}}^{\mathrm{app}}$ value in nonionic micelles $(=4.02$, Table 1$)$. First of all, with such approach the screening of the surface charge even by $4 \mathrm{M} \mathrm{KCl}$ is far from being complete. Also, the $\Psi$ value in micelles of the zwitterionic surfactant is surprisingly high (Table 1). This should be attributed to the local electrostatic potentials in the interfacial layer. Finally, the $|\Psi|$ value in anionic micelles in the presence of $0.1 \mathrm{M} \mathrm{NaCl}$ is approximately two times lower than in the cationic micelles at the same ionic strength. Similar proportion 
was observed with $N, N^{\prime}$-di- $n$-octadecylrhodamine as indicator [2, 21], but the absolute values are markedly lower.

These conclusions rest on the assumption of the equality of $\mathrm{p} K_{\mathrm{a}}^{\mathrm{i}}$ in all kinds of micelles. This, in turn, is true at least if the location and hydration of the indicator and especially of the ionizing group is similar in different pseudophases. We used MD modeling to clarify these issues.

\subsection{Molecular dynamics modeling of indicator localization}

Using the MD simulations the location of the phenolic moiety of the dye molecule in the micelles was estimated by the analysis of the distribution functions of the distances (DFD) between the micelle center of mass (COM) and the chosen atoms of the dye. We selected two atoms: i) the $\mathrm{O}$ atom of the dissociating hydroxyl group (it will be further denoted $\mathrm{O}_{\mathrm{OH}}$ ) and ii) the $\mathrm{C}$ atom of the hydrocarbon tail bonded to the benzene ring (denoted $C_{\alpha}$ ). The graphs are shown in Fig. 5. The peaks on these DFDs indicate the preferable region of the micelle where the particular atom is located. For comparison, DFDs between the micelle $\mathrm{COM}$ and the atoms $\mathrm{S}$ or $\mathrm{N}$ of the surfactant ions are calculated, as well, because they indicate the location of the micelle surface layer.

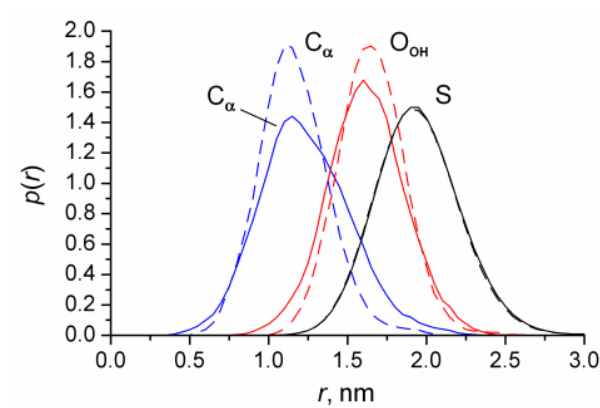

SDS

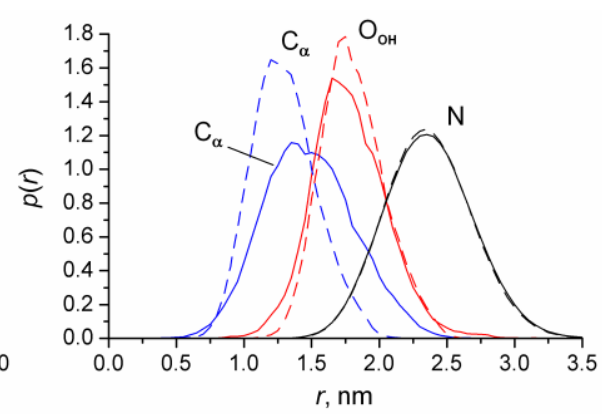

CTAB

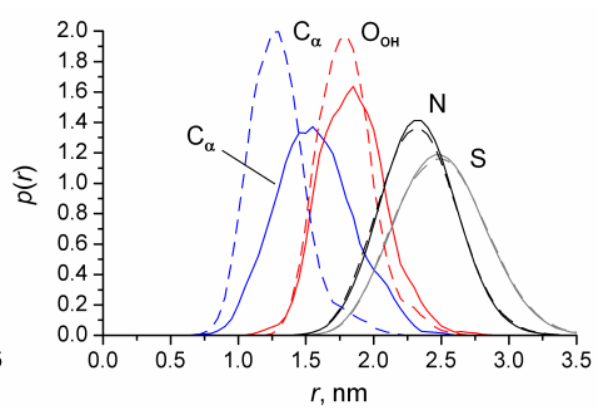

CDAPS

Fig. 5 Distribution functions of the distances between the micelle COM and the $\mathrm{C}_{\alpha}, \mathrm{O}_{\mathrm{OH}}$ atoms of DDP or $\mathrm{S}(\mathrm{N})$ atoms of the surfactant ions; solid curves are for the neutral form, dashed curves are for the anionic form.

The results show that the hydroxyl group is situated in the surface layer and it is not immersed into the micelle, while the $\mathrm{C}_{\alpha}$ atom is situated much deeper in it. Importantly, the difference between the average 
location of the neutral and anionic forms is very small, the corresponding peaks almost coincide. A notable difference is observed for the $\mathrm{C}_{\alpha}$ atom in CDAPS micelles only.

\subsection{Modeling of indicator orientation}

Deeper understanding of the dye molecule location in the micelle is provided by its orientation with respect to the micelle surface. To quantify it, we introduced the pitch angle $\theta$ defined as $\angle$ (the micelle $\mathrm{COM}$, the $\mathrm{C}_{\alpha}$ atom of DDP, the $\mathrm{O}_{\mathrm{OH}}$ atom of DDP). Its distribution functions shows show the molecule is aligned. The definition of the angle and the results of calculations are shown in Fig. 6.
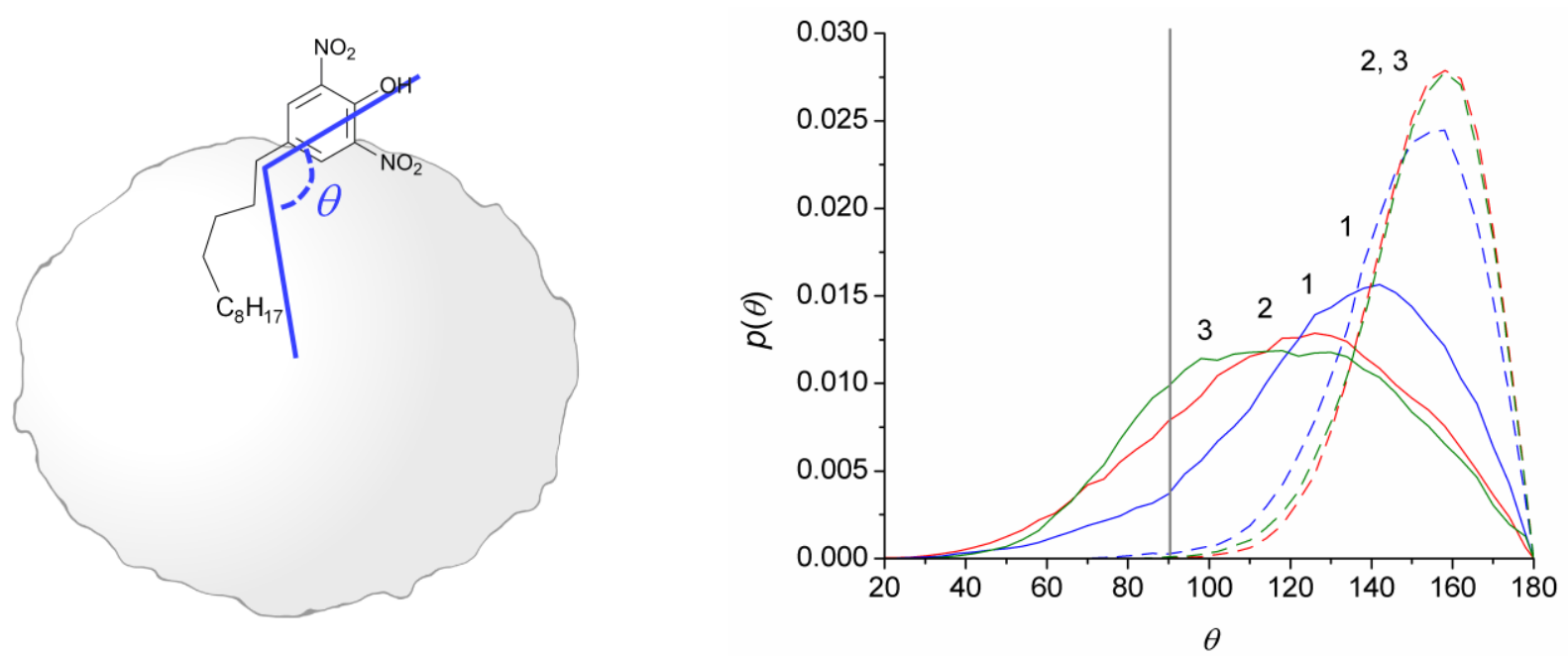

Fig. 6 Left: the definition of the angle $\theta$ (gray zone depicts the micelle hydrocarbon core); right: the distribution functions of $\theta$. $1-$ SDS solution, $2-$ CTAB solution, $3-$ CDAPS solution; solid curves are for the neutral form, dashed curves are for the anionic form.

For the anionic form, the $\theta$ values around $160^{\circ}$ are typical for all micelles. This corresponds to the orientation that is roughly parallel to the micelle radius with the hydroxyl group pushed towards the bulk phase. A similar picture is observed for the neutral form in SDS micelles, but the maximum is at $140^{\circ}$ and the peak is wider that means a stronger inclination of the molecule. In CTAB and CDAPS micelles this effect is even more pronounced: the high probability of the values $80-120^{\circ}$ means that the orientation with the molecule lying roughly parallel to the micelle surface is populated, too. 


\subsection{Modeling of indicator microenvironment}

Apart from the location of the dye molecule the composition of the medium where it resides (its microenvironment) is important as it ultimately determines the $\mathrm{p} K_{\mathrm{a}}^{\mathrm{i}}$ shift upon binding by the micellar pseudophase. We employed the same approach for its description as in our previous works devoted to the Reichardt's solvatochromic indicators and the azo dye [22, 32-34]. The atoms of the solution that surround the phenolic moiety of the DDP molecule (i.e. which are located within $0.4 \mathrm{~nm}$ of at least one of its atoms) were classified into three categories: atoms of water molecules, the atoms of surfactant head groups, and the atoms of surfactant hydrocarbon tails. The average numbers of atoms in these categories characterize the microenvironment of the dye molecule. The results are shown in Fig. 7.
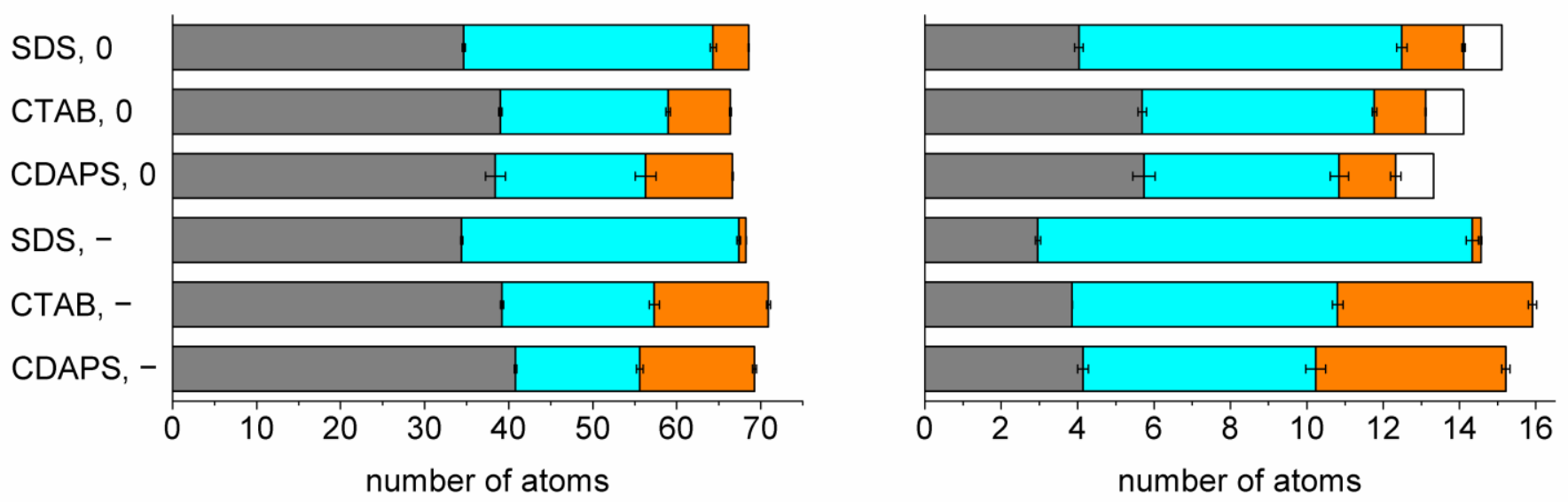

Fig. 7 Numbers of atoms of various kinds in the microenvironment of the phenolic moiety of the DDP molecule (left) and of the hydroxyl $\mathrm{O}$ atom (right); gray: atoms of hydrocarbon tails, blue: atoms of water molecules, orange: atoms of surfactant head groups, white: the $\mathrm{H}$ atom in the hydroxyl group.

In the SDS micelles, the dye is much better hydrated than in the CTAB and CDAPS ones. The difference between CTAB and CDAPS is quite small (10-15\%). Moreover, in CDAPS micelles only the positively charged $\left[\mathrm{CH}_{2}-\mathrm{N}\left(\mathrm{CH}_{3}\right)_{2}-\mathrm{CH}_{2}\right]^{+}$fragments contribute to the microenvironment of the hydroxyl group, while there are no contacts with the negatively charged $\mathrm{SO}_{3}{ }^{-}$fragments. The contact of the whole dye molecule with the $\mathrm{SO}_{3}^{-}$fragments is non-zero but very small. Therefore, the dye should be considered as situated in the electric field with positive potential despite the surfactant zwitter-ions as a whole are neutral. This should have consequences related to the value of $\mathrm{p} K_{\mathrm{a}}^{\text {app }}$ in these micelles. 
Importantly, for both the whole molecule and its individual hydroxyl group the microenvironment remains almost unchanged upon going from the neutral form to the anionic one in all micelles. The differences are 2.9 atoms in SDS, 0.9 atoms in CTAB, and 1.0 atom in CDAPS, which are less than for the other dyes that we studied previously, the Reichardt's betaines [32-34] and the azo dye [22]. This fact together with the similarity of the location of these two forms provides microscopic justification of the application of the proposed dye as a suitable probe of the micelle electrostatic potential.

In order to elucidate the role of the hydrocarbon tail length, a dye with $\mathrm{C}_{5} \mathrm{H}_{11}$ group, $\mathrm{PDP}$, was examined. The location of PDP in SDS micelles is shown in Supporting Information, Fig. S1. In general, both forms of PDP are situated $0.1-0.2 \mathrm{~nm}$ closer to water phase than DDP, which shows that the length of the hydrocarbon radical does affect, albeit weakly, the dye location in the micelles.

\subsection{Comparing with data obtained using other indicators}

Most experimental data obtained in the present study refer to the ionic strength $0.10 \mathrm{M}$. This is because of the low $\mathrm{p} K_{\mathrm{a}}^{\mathrm{app}}$ values in cationic micelles, which requires using relatively high $\mathrm{HCl}$ and $\mathrm{HBr}$ concentrations. However, the obtained $\mathrm{p} K_{\mathrm{a}}^{\mathrm{app}}$ values can be re-calculated to the ionic strength (in this case it is the counterion concentration) of $0.05 \mathrm{M}$ using the well known slopes of the $\mathrm{p} K_{\mathrm{a}}^{\mathrm{app}}$ vs $\operatorname{logarithm}$ of counterion concentration dependences [2, 3, 21], Eq. (4, 5) for cationic and anionic micelles, respectively.

$$
\begin{aligned}
& \left(\frac{\partial \mathrm{p} K_{\mathrm{a}}^{\mathrm{app}}}{\partial \log \left[\mathrm{Br}_{\mathrm{w}}^{-}\right]}\right)_{T}=\beta \\
& \left(\frac{\partial \mathrm{p} K_{\mathrm{a}}^{\mathrm{app}}}{\partial \log \left[\mathrm{Na}_{\mathrm{w}}^{+}\right]}\right)_{T}=-\beta
\end{aligned}
$$

Here, $\beta$ is the degree of counterion binding $[2,3]$. It means that the $|\Psi|$ values in SDS, CTAB, and CPC micelles as obtained via Eq. (3) should be increased by $13 \mathrm{mV}$, using the $\beta=0.75$ value. For example, $\Psi$ is equal to $-95 \mathrm{mV}$ for $\mathrm{SDS}$ and to $+171 \mathrm{mV}$ for CTAB micelles at counter-ions $\mathrm{Na}^{+} \mathrm{or} \mathrm{Br}^{-}$ concentration of $0.05 \mathrm{M}$. 
In Table 2 and 3, the $\Psi$ values estimated obtained with 2,6-dinitro-4- $n$-dodecylphenol are compared with the data obtained with other indicators, most often applied for $\Psi$ determination, first of all the hydrophobic hydroxycoumarins.

Table 2. The values of the electrostatic potential of SDS micelles estimated by various methods

\begin{tabular}{lc}
\hline Indicator & $\Psi, \mathrm{mV}$ \\
\cline { 2 - 2 } & $0.05 \mathrm{M} \mathrm{Na}^{+}$ \\
2,6-Dinitro-4-n-dodecylphenol, this work & $-95^{\mathrm{a}}$ \\
4-Heptadecyl-7-hydroxycoumarin & $-114^{\mathrm{b}}$ \\
4-Octadecyloxy-1-naphthoic acid & $-87^{\mathrm{c}}$ \\
Standard Reichardt's dye d,e & -95 \\
$n$-Decylfluorescein ${ }^{\text {e }}$ & $-110(-144)^{\mathrm{f}}$ \\
$N, N^{\prime}$-Di- $n$-octadecylrhodamine ${ }^{\mathrm{e}}$ & -59 \\
Calculation via $\quad$ Ohshima-Healy-White & $-66^{\mathrm{g}}$ \\
equation, ref. [55] & \\
\hline
\end{tabular}

${ }^{\text {a }}$ At $0.10 \mathrm{M} \mathrm{Na}^{+}, \Psi=-82 \mathrm{mV}$, this work. ${ }^{\mathrm{b}}$ At $0.10 \mathrm{M} \mathrm{Na}^{+}, \Psi=-95 \mathrm{mV}$, ref. [15]. ${ }^{\mathrm{c}}$ From the value -93 $\mathrm{mV}$ in ref. [20] recalculated to $\mathrm{Na}^{+}$concentration of $0.05 \mathrm{M} .{ }^{\mathrm{d}}$ 4-(2,4,6-triphenylpyridinium-1-yl)-2,6diphenyl phenolate. ${ }^{\mathrm{e}}$ Ref. $[2,3] .{ }^{\mathrm{f}}$ The values in parenthesis are determined using the constants of twostep equilibria of $n$-decylfluorescein. ${ }^{g}$ Calculated using the values of micellar radius, molecular area of the ionic head group, and degree of counterions binding $2.0 \mathrm{~nm}, 0.60 \mathrm{~nm}^{2}$, and 0.75 , respectively.

Table 3. The values of the electrostatic potential of CTAB and CDAPS micelles estimated by various methods

\begin{tabular}{|c|c|c|c|}
\hline \multirow[t]{2}{*}{ Indicator } & \multicolumn{3}{|c|}{$\Psi, \mathrm{mV}$} \\
\hline & \multicolumn{2}{|c|}{ CTAB micelles } & CDAPS micelles \\
\hline Ionic strength $=$ & $0.05 \mathrm{M}$ & $4.0 \mathrm{M} \mathrm{KCl}$ & $0.05-0.10$ \\
\hline 2,6-Dinitro-4-n-dodecylphenol, this work & +171 & +108 & +120 \\
\hline $\begin{array}{l}\text { 4-Heptadecyl-7-hydroxycoumarin, 4-undecyl-7- } \\
\text { hydroxycoumarin, and 4-octadecyloxy-1- } \\
\text { naphthoic acid }^{\text {a }}\end{array}$ & $+118^{b}$ & $-^{\mathrm{c}}$ & - \\
\hline Standard Reichardt's dye ${ }^{d}$ & $+99(+117)^{\mathrm{e}}$ & +30 & +65 \\
\hline$n$-Decylfluorescein ${ }^{\mathrm{d}}$ & $+122(+103)^{\mathrm{f}}$ & $+23(+15)^{\mathrm{f}}$ & $+55(+46)^{\mathrm{f}}$ \\
\hline$N, N^{\prime}$-Di- $n$-octadecylrhodamine ${ }^{\mathrm{d}}$ & +99 & +16 & +36 \\
\hline
\end{tabular}



ref. [55 ${ }^{g}$

${ }^{a}$ Average values from ref. [11, 14, 20, 54] recalculated to $\mathrm{Br}^{-}$concentration of $0.05 \mathrm{M}$ via Eq. (4), see also ref. [21]. ${ }^{\mathrm{b}}$ At $\mathrm{NaBr}$ concentration of $0.05 \mathrm{M}$ the value ca. $+90 \mathrm{mV}$ was given in Fig. 6 in ref. [11]. ${ }^{\mathrm{c}}$ For $n$-dodecyltrimethylammonium chloride micelles in $4.0 \mathrm{M} \mathrm{NaCl}$ solution, $\Psi=+43 \mathrm{mV}$ with 4heptadecyl-7-hydroxycoumarin, ref. [54]. ${ }^{\mathrm{d}}$ Ref. [2, 3]. ${ }^{\mathrm{e}}$ Recalculated via Eq. (4) from the value $+141 \mathrm{mV}$ determined at low ionic strength published in ref. [14]. ${ }^{\mathrm{f}}$ The values in parenthesis are determined using the constants of two-step equilibria of $n$-decylfluorescein. ${ }^{\mathrm{g}}$ Calculated using the values of micellar radius, molecular area of the ionic head group, and degree of counterions binding $2.6 \mathrm{~nm}, 0.474 \mathrm{~nm}^{2}$, and 0.73 , respectively.

With 4-heptadecyl-7-hydroxycoumarin, the values $\Psi=-122,-110$, and $-95 \mathrm{mV}$ were obtained in SDS micellar solutions with ionic strength $(\mathrm{NaCl}) 0.025,0.065$, and $0.102 \mathrm{M}$, respectively [15]. Fernandez and Fromherz [11] and Drummond and Grieser [54] reported $\Psi$ values obtained with 4undecyl- and 4-heptadecyl-7-hydroxycoumarins, respectively; these data agree with those published by Hartland et al. [15] and are considered in ref. [21]. The 4-octadecyloxy-1-naphthoic acid was also used [20]. As the ionic strength in these studies [11, 20, 54] was substantially lower compared to our experiments, the corresponding corrections would make the difference smaller. Only these recalculated values are compiled in Table 3. However, the electrostatic potential estimated with the coumarin indicators $[11,15,54]$ shows somewhat more negative $\Psi$ values than were estimated with 2,6-dinitro-4dodecylphenol.

It should be stated that, in the case of SDS micelles, the proposed indicator 2,6-dinitro-4dodecylphenol provides the $\Psi$ values agreeing roughly with other estimates (Table 2). Further pro et contra for using just this indicator should be followed from the results of MD modeling, see above. This is not the case with the CTAB micelles at $0.05 \mathrm{M} \mathrm{Br}^{-}$(Table 3).

For CTAB micellar solutions, the $\Psi$ values were obtained by several authors with the hydrophobic coumarins at ionic strengths $<0.05 \mathrm{M}[11,14,20,54]$. In Table 3, these and some other values are recalculated to $\left[\mathrm{Br}_{\mathrm{w}}{ }^{-}\right]=0.05 \mathrm{M}$ using Eq. (4). In addition, we obtained some values using the Reichardt's 
betaine dye, $n$-decylfluorescein, and $N, N^{\prime}$-di- $n$-octadecylrhodamine $[2,3,21]$. They are also compiled in Table 3.

The inspection of Table 3 allows stating that the indicator 2,6-dinitro-4-dodecylphenol shows substantially more positive $\Psi$ values in cationic micelles: in the case of CTAB micelles at $0.05 \mathrm{M} \mathrm{Br}^{-}$, the results obtained with the new indicator are evidently different (Table 3).

The overestimate of the $\Psi$ values obtained with 2,6-dinitro-4-dodecylphenol may also be proven using the Ohshima-Healy-White equation [55], which allows calculating the electrostatic potential values for well-defined surfactant micelles [2,21], although these results depend to some degree on the values of the molecular area of the head groups and $\beta$. This equation for spherical micelles is given below, Eq. (6).

$$
\frac{1-\beta}{s_{\mathrm{i}}}=\frac{2 \varepsilon \varepsilon_{o} \kappa R T}{F} \sinh (Y / 2)\left(1+\frac{2}{\kappa r \cosh ^{2}(Y / 4)}+\frac{8 \ln [\cosh (Y / 4)]}{(\kappa r)^{2} \sinh ^{2}(Y / 2)}\right)^{\frac{1}{2}}
$$

Here, $s_{\mathrm{i}}$ is the area of charged head group (molecular area), $Y=\Psi F / R T, \kappa$ is the Debye length, $\varepsilon_{o}$ $=8.854 \times 10^{-12} \mathrm{~F} \mathrm{~m}^{-1}, \varepsilon_{o}=78.5$ at $T=298.15 \mathrm{~K}$. Actually, the left hand side in Eq. (6) is the surface charge density.

Eq. (6) may also be used for verifying the experimentally estimated value $\Psi=+171 \mathrm{mV}$ for CTAB micelles. At $\left[\mathrm{Br}^{-}\right]=0.05 \mathrm{M}$ this value corresponds to a micellar surface charge density value of 2.45 elementary charges per $\mathrm{nm}^{2}$, if the micellar radius is $2.6 \mathrm{~nm}$. If $\beta=0.75$, the molecular area of the head group is $0.10 \mathrm{~nm}^{2}$, which is impossible taking the van-der-Waals value of $0.38 \mathrm{~nm}^{2}$ [56]. Even for $\beta=$ $0.60, s_{\mathrm{i}}$ is also as low as $0.16 \mathrm{~nm}^{2}$. So, this also confirms the overestimated $\Psi$ value for cationic surfactant micelles obtained with the 2,6-dinitro-4-dodecylphenol. Indeed, if, for instance, $\Psi$ equals to $100 \mathrm{mV}$, the surface charge density is 0.762 , and the molecular area at $\beta=0.75$ and 0.60 is 0.328 and $0.525 \mathrm{~nm}^{2}$, respectively.

Furthermore, for CTAB micelles in $4.0 \mathrm{M} \mathrm{KCl}$ solution, $\Psi=+16 \mathrm{mV}$ and $+30 \mathrm{mV}$ as obtained with $N, N^{\prime}$-di- $n$-octadecylrhodamine and Reichardt's dye, respectively [2], while the value of $+108 \mathrm{mV}$ was obtained for $\mathrm{CTAB}$ with $4.0 \mathrm{M} \mathrm{KCl}$ with the hydrophobic dinitrophenol in the present study (under these conditions, the CTAB micelles convert into the CTAC ones). 
Moreover, whereas for the zwitterionic CDAPS micelles, the $\Psi$ value obtained with $N, N^{\prime}$-di- $n$ octadecylrhodamine and Reichardt's dye equal to +36 and $+65 \mathrm{mV}$, respectively [2], the application of 2,6-dinitro-4-dodecylphenol leads to $\Psi=+120 \mathrm{mV}$ (Tables 1, 3).

As one of possible explanations it can be assumed that the strong decrease in the $\mathrm{p} K_{\mathrm{a}}^{\text {app }}$ value of 2,6dinitro-4-dodecylphenol reflects only the local electrostatic potentials at the location of the ionizing group of the indicator. However, the simulations in comparison with another phenolic indicator, cation of the Reichardt's dye [32-34], does not support such explanation, as it is seen in Table 3. Also, the orientation of the 2,6-dinitro-4-dodecylphenolate, $\mathrm{A}^{-}$, in CTAB, CDAPS, and SDS micelles is similar, but the negative $\Psi$ value in SDS is certainly not overestimated.

A probable reason may be some specific interaction in the micelles with alkylammonium moiety. Indeed, the contacts of the phenolate oxygen of $\mathrm{A}^{-}$with the cationic headgroups of surfactants are evident (Fig. 7). The same refers to the nitro groups, which favor the delocalization of the negative charge in the indicator anion, thus stabilizing it and decreasing the $\mathrm{p} K_{\mathrm{a}}^{\mathrm{i}}$ value. This, in turn, leads to overestimating the $\Psi$ value, if such specific effect is not taken into account.

The strong delocalization of the negative charge in nitrophenolates is known to reduce the $\mathrm{p} K_{\mathrm{a}}$ increase in going from water to polar non hydrogen bond-donor solvents. For example, in dimethylsulfoxide (DMSO), the rise of $\mathrm{p} K_{\mathrm{a}}$ is 6.4 units for phenol [57], 3.8 for 2-nitrophenol [57], 1.66 for 2,5-dinitrophenol [58], 1.2 for 2,6-dinitrophenol [57], and 0.9 for 2,4-dinitrophenol [58]. For the lastnamed indicator, the $\mathrm{p} K_{\mathrm{a}}$ even drops from 4.11 in water to 3.56 in 65 vol. \% aqueous DMSO [59]. In our case, the mechanism of the additional stabilization of the anion is somewhat different from that in DMSO, and probably consists in further shifting the electron density from the phenolate oxygen caused by the interaction of the electrophilic electronically unsaturated $\mathrm{NO}_{2}$ substituents with the tetraalkylammonium groups.

To support this hypothesis we used the data reported by Seguchi [50]. In his work, the $\mathrm{p} K_{\mathrm{a}}^{\text {app }}=2.40$ value of 2,4-dinitrophenol in CTAB solutions (in the presence of $3 \%$ ethanol, $30{ }^{\circ} \mathrm{C}$ ) [50] corresponds to the same value $\left(2.37\right.$ in $\left.0.016 \mathrm{M} \mathrm{CTAB}, 0.05 \mathrm{M} \mathrm{KBr}, 25^{\circ} \mathrm{C}\right)$ of this indicator obtained in our laboratory 
[52]. Therefore, the value $\mathrm{p} K_{\mathrm{a}}^{\mathrm{app}}=5.86$, reported by Seguchi for the 2-nitro-4- $n$-nonylphenol in CTAB micellar solutions, can be attributed to the $\mathrm{Br}^{-}$concentration of ca. $0.05 \mathrm{M}$. In Brij 35 micellar solutions, $\mathrm{p} K_{\mathrm{a}}^{\mathrm{app}}=8.52$ for the same indicator [50], which allows estimating the $\Psi$ value in CTAB micelles as $+157 \mathrm{mV}$. Though it is again somewhat lower compared to the $+171 \mathrm{mV}$ value obtained with 2,6 -dinitro4-dodecylphenol, but still overestimated. Indeed, by Eq. (6) the $s_{\mathrm{i}}=0.130$ and $0.209 \mathrm{~nm}^{2}$ values can be estimated for $\beta=0.75$ and 0.60 , respectively. These molecular areas of the head groups are again unlikely small, although the indicator used bears only one nitro group.

Note, that for the anionic surfactant, the data with 2-nitro-4-n-nonylphenol [50] gives the $\Psi$ value around $\mathrm{o}-90 \mathrm{mV}$, which is close to that obtained with 2,6-dinitro-4-dodecylphenol ( $-95 \mathrm{mV}$, see above). This supports the hypothesis of specific interactions between our indicator and ionic head groups only in the case of cationic and zwitterionic surfactants.

Accordingly, it may be concluded that the excessive polarizability of the electrophilic $\mathrm{NO}_{2}$ groups may cause a substantial change in the intrinsic value, $\mathrm{p} K_{\mathrm{a}}^{\mathrm{i}}$, of corresponding indicators in Stern layer of micelles with alkylammonium groups. This results in overestimation of the $\Psi$ value. In contrast, 2,6dinitro-4-dodecylphenol is quite suitable for examining micelles of anionic surfactants.

Therefore, we performed MD simulations for 2-nitro-4-n-nonylphenol. The location of NNP in CTAB micelles is shown in Supporting Information, Fig. S2. The difference between the locations of NNP and DDP is of the same magnitude, despite the absence of one nitro group.

In order to make these comparisons clearer, the average distances of the $\mathrm{C}_{\alpha}$ and $\mathrm{O}$ atoms to the micelle COM were computed for each case. The values for DDP are collected in Table 4, while for other dyes the results are listed in Table 5. The difference of the quantities between anionic and neutral forms can easily be calculated, which are also listed in Table 4 (the 'delta' values).

Table 4. Average distances of the $\mathrm{C}_{\alpha}$ and $\mathrm{O}$ atoms of DDP to the micelle COM (nm).

\begin{tabular}{|c|c|c|}
\hline micelles & $\mathrm{C}_{\alpha}$ atom & $\mathrm{O}_{\mathrm{OH}}$ atom \\
\hline & delta & delta \\
\hline
\end{tabular}




\begin{tabular}{lcccccc} 
SDS & 1.23 & 1.16 & -0.07 & 1.62 & 1.66 & 0.04 \\
CTAB & 1.48 & 1.30 & -0.18 & 1.78 & 1.81 & 0.03 \\
CDAPSn & 1.57 & 1.30 & -0.27 & 1.85 & 1.80 & -0.05 \\
\hline
\end{tabular}

Table 5. Average distances of the $\mathrm{C}_{\alpha}$ and $\mathrm{O}$ atoms of PDP and NNP to the micelle COM (nm).

\begin{tabular}{llcccc}
\hline dye & micelles & \multicolumn{2}{c}{$\mathrm{C}_{\alpha}$ atom } & \multicolumn{2}{c}{$\mathrm{O}_{\mathrm{OH}}$ atom } \\
\cline { 3 - 6 } & & $\mathrm{HA}$ & $\mathrm{A}^{-}$ & $\mathrm{HA}$ & $\mathrm{A}^{-}$ \\
$\mathrm{NDP}$ & $\mathrm{SDS}$ & 1.42 & 1.27 & 1.68 & 1.73 \\
$\mathrm{NNP}$ & $\mathrm{CTAB}$ & 1.31 & 1.40 & 1.64 & 1.85 \\
\hline
\end{tabular}

The microenvironment of NNP is shown in Fig. S3. Interestingly, removing one nitro group causes different shifts in hydrations of the neutral and anionic forms. As a result, the difference between the hydrations of these forms increases in comparison with DDP and becomes 4.0 atoms in CTAB micelles.

\section{Conclusions}

In search of an optimal acid-base indicator for examining micelles of ionic surfactants, 2,6-dinitro-4- $n$ dodecylphenol was synthesized and the indices of the apparent ionization constants, $\mathrm{p} K_{\mathrm{a}}^{\text {app }}$, were obtained by the spectrophotometric method supplemented by potentiometric $\mathrm{pH}$ determination. Molecular Dynamics simulations demonstrate that in micelles of any kind, the location of the HA and the $\mathrm{A}^{-}$forms is quite similar. Additionally, simulations were made for two other hydrophobic nitrophenols and their anions in micelles.

The values of the electrostatic interfacial potential of the micelles, that is the potential of the Stern layer, $\Psi$, were determined by the standard procedure, using the $\mathrm{p} K_{\mathrm{a}}^{\text {app }}$ value of the indicator in nonionic micelles as the indices of the intrinsic ionization constant $\mathrm{p} K_{\mathrm{a}}^{\mathrm{i}}$ in ionic micelles. Thus obtained $\Psi$ values in the micelles of surfactants bearing alkylammonium and alkylpyridinium groups appeared to be much higher than those either estimated using other indicators or calculated by the Ohshima-Healy-White equation. This was explained in terms of the specific interactions between the nitro groups of the indicator 
with alkylammonium or pyridinium groups in the Stern layer of the micelles: these interactions additionally stabilize the $\mathrm{A}^{-}$form of the indicator, thus decreasing the $\mathrm{p} K_{\mathrm{a}}^{\mathrm{i}}$ value. The latter is therefore difficult to predict. On the other hand, the indicator 2,6-dinitro-4- $n$-dodecylphenol is suitable for examining anionic micelles. So, the $\Psi$ value for the SDS micelles is $-95 \mathrm{mV}$ (at ionic strength $0.05 \mathrm{M}$ ).

\section{Acknowledgements}

The authors express their gratitude to the Ministry of Education and Science of Ukraine for the financial support of this study via grant number 0117 U004966.

\section{Appendix A. Supplementary data.}

\section{References}

[1] F. Grieser, C.J. Drummond, The physicochemical properties of self-assembled surfactant aggregates as determined by some molecular spectroscopic probe techniques, J. Phys. Chem. 92 (1988) 55805593. http://dx.doi.org/10.1021/j100331a012

[2] N.O. Mchedlov-Petrossyan, Protolytic equilibrium in lyophilic nanosized dispersions: Differentiating influence of the pseudophase and salt effects, Pure Appl. Chem. 80 (2008) 14591510. http://dx.doi.org/10.1351/pac200880071459

[3] N.O. Mchedlov-Petrossyan, N.A. Vodolazkaya, N.N. Kamneva, Acid-base equilibrium in aqueous micellar solutions of surfactants, in: D. Bradburn, J. Bittinger (Eds.) Micelles: Structural biochemistry, formation and functions \& usage, Nova Science Publishers, N. Y., 2013, pp. 1-71.

[4] O. Yu. Konovalova, E. A. Reshetnyak, T. B. Pochinok, P. V. Anisimovich, N. N. Nikitina, N. V. Ivchenko, Solvatochromic and protolytic properties of the indicators in the solidified gelatin gel medium, Colloids Surf. A 529 (2017) 26-32; http://dx.doi.org/10.1016/j.colsurfa.2017.05.035

[5] B. Boruah, B. Gohain, P. M. Saikia, M. Borah, R.K. Dutta, Acid-basee equilibrium of neutral red in aqueous nonionic surfactant-polymer systems, J. Mol. Liquids, 160 (2011) 50-56; http://dx.doi.org/10.1016/j.molliq.2011.02.014

[6] E. N. Obukhova, N. O. Mchedlov-Petrossyan. N. A. Vodolazkaya, L. D. Patsenker, A. O. Doroshenko, A. I. Marynin, B.M. Krasovitskii. Absorption, fluorescence, and acid-base equilibria of rhodamines in micellar media of sodium dodecyl sulfate. Spectrochimica Acta Part A: Molecular and Biomolecular Spectroscopy. 170 (2017) 138-144. http://dx.doi.org/10.1016/j.saa.2016.07.002 
[7] M. V. Caruana, M. C. Fava, D. C. Magri, A colorimetric and fluorimetric three-input inverted enabled OR logic array by self-assembly of a rhodamine probe in micelles. Asian J. Org. Chem. 4 (2015) 239-243. http://dx.doi.org/10.1002/ajoc.201402236

[8] G.S. Hartley, J.W. Roe, Ionic concentrations at interfaces, Trans. Faraday Soc. 35 (1940) 101-109. http://dx.doi.org/10.1039/tf9403500101

[9] P. Mukerjee, K. Banerjee, A study of the surface $\mathrm{pH}$ of micelles using solubilized indicator dyes, J. Phys. Chem. 68 (1964) 3567-3574. http://dx.doi.org/10.1021/j100794a022

[10] P. Fromherz, A new method for investigation of lipid assemblies with a lipoid $\mathrm{pH}$ indicator in monomolecular films, Biochem. Biophys. Acta $323 \quad$ (1973) 326-334. http://dx.doi.org/10.1016/0005-2736(73)90155-7

[11] M.S. Fernandez, P. Fromherz, Lipoid pH indicators as probes of electrical potential and polarity in micelles, J. Phys. Chem. 81 (1977) 1755-1761. http://dx.doi.org/10.1021/j100533a009

[12] N. Funasaki, The effect of the solvent property of the surfactant micelle on the dissociation constants of weak electrolytes, Nippon Kagaku Kaishi, (1976) no. 5, 722-726.

[13] N. Funasaki, Micellar effects on the kinetics and equilibrium of chemical reactions in salt solutions, J. Phys. Chem. 83 (1979) 1998-2003. http://dx.doi.org/10.1021/j100478a014

[14] C.J. Drummond, F. Grieser, T.W. Healy, A single spectroscopic probe for the determination of both the interfacial solvent properties and electrostatic surface potential of model lipid membranes, Farad. Discuss. 81 (1986) 95-106. http://dx.doi.org/10.1039/dc9868100095

[15] G.V. Hartland, F. Grieser, L.R. White, Surface potential measurements in pentanol-sodium dodecyl sulphate micelles, J. Chem. Soc. Faraday Trans. 1, 83 (1987) 591-613. http://dx.doi.org/10.1039/F19878300591

[16] S. Lukac, Surface potential at surfactant and phospholipid vesicles as determined by amphiphilic $\mathrm{pH}$ indicators. J. Phys. Chem. 87 (1983) 5045-5050. http://dx.doi.org/10.1021/j150642a053

[17] G. P. Gorbenko, N. O. Mchedlov-Petrossyan, T. A. Chernaya. Ionic equilibria in microheterogeneous systems. Protolytic behaviour of indicator dyes in mixed phosphatidylcholinediphosphatidylglycerol liposomes. J. Chem. Soc., Faraday Transactions, 94 (1998) 2117-2125. http://dx.doi.org/10.1039/A800771C

[18] S. Yamaguchi, K. Bhattacharyya, T. Tahara, Acid-base equilibrium at an aqueous interface: $\mathrm{pH}$ spectrometry by heterodyne-detected electronic sum frequency generation, J. Phys. Chem. C 115 (2011) 4168-4173. http://dx.doi.org/10.1021/jp1113174

[19] T.P. Souza, D. Zanette, A.E. Kawanami, L. de Rezende, H.M. Ishiki, A.T. do Amaral, H. Chaimovich, A. Agostinho-Neto, I.M. Cuccovia, $\mathrm{pH}$ at the micellar interface: Synthesis of $\mathrm{pH}$ probes derived from salicylic acid, acid-base dissociation in sodium dodecyl sulfate micelles, and Poisson-Boltzmann simulation, J. Colloid Interface Sci. 297 (2006) 292-302. http://dx.doi.org/10.1016/j.jcis.2005.10.008 
[20] B. Lovelock, F. Grieser, T.W. Healy, Properties of 4-octadecycloxy-1-naphthoic acid in micellar solutions and in monolayer films absorbed onto silica attenuated total reflectance plates, J. Phys. Chem. 89 (1985) 501-507. http://dx.doi.org/10.1021/j100249a027

[21] N.O. Mchedlov-Petrossyan, N.A. Vodolazkaya, A.G. Yakubovskaya, A.V. Grigorovich, V.I. Alekseeva, L.P. Savvina, A novel probe for determination of electrical surface potential of surfactant micelles: N,N'-di-n-octadecylrhodamine, J. Phys. Org. Chem. 20 (2007) 332-344. http://dx.doi.org/10.1002/poc. 1150

[22] N. O. Mchedlov-Petrossyan, V. S. Farafonov, A. V. Lebed. Examining surfactant micelles via acidbase indicators: Revisiting the pioneering Hartley-Roe 1940 study by molecular dynamics modeling. J. Mol. Liquids, 264 (2018) 683-690. https://doi.org/10.1016/j.molliq.2018.05.076

[23] N. O. Mchedlov-Petrossyan, A. V. Plichko, A. S. Shumakher, Acidity of microheterogeneous systems: Effect of nonionic admixtures on acid-base equilibria of dyes bound to micelles of ionogenic surfactants, Chem. Phys. Rep. 15 (1996) 1661-1678.

[24] N. O. Mchedlov-Petrossyan, Ionization and tautomeric interconversions of rhodamine dyes, Zh. Fiz. Khim. 59 (1985) 3000-3004 (in Russian).

[25] E.B. Tada, L.P. Novaki, O.A. El Seoud, Solvatochromism in cationic micellar solutions: Effects of the molecular structures of the solvatochromic probe and the surfactant headgroup, Langmuir 17 (2001), 652-658. http://dx.doi.org/10.1021/la0011351

[26] P. Sabatino, A. Szczygiel, D. Sinnaeve, M. Hakimhashemi, H. Saveyn, J.C. Martins, P. Van der Meeren, NMR study of the influence of $\mathrm{pH}$ on phenol sorption in cationic CTAB micellar solution, Colloids Surf. A 370 (2010) 42-48. http://dx.doi.org/10.1016/j.colsurfa.2010.08.042

[27] B.H. Morrow, Y. Wang, J.A. Wallace, P.H. Koenig, J.K. Shen, Simulating pH titration of a single surfactant in ionic and nonionic surfactant micelles, J. Phys. Chem. B 115 (2011) 14980-14990. http://dx.doi.org/10.1021/jp2062404

[28] B.H. Morrow, P.H. Koenig, J.K. Shen, Constant pH simulations of pH responsive polymers, J. Chem. Phys. 137 (2012) 194902. http://dx.doi.org/10.1063/1.4766313

[29] B. Lukanov, A. Firoozabadi. Specific ion effects on the self-assembly of ionic surfactants: A molecular thermodynamic theory of micellization with dispersion forces, Langmuir 30 (2014) 6373-6383. http://dx.doi.org/10.1021/la501008x.

[30] C. Aliaga, L. Briones, M. C. Rezende and C. Tirapegui, The thermochromism of the ET(30) betaine in a micro-heterogeneous medium: a spectral and dynamics simulation study, J. Colloid Interface Sci. 349 (2010) 565-570. http://dx.doi.org/10.1016/j.jcis.2010.05.088

[31] A. Kyrychenko, A molecular dynamics model of rhodamine-labeled phospholipid incorporated into a lipid bilayer, Chem. Phys. Lett. 485 (2010) 95-99. http://dx.doi.org/10.1016/j.cplett.2009.12.015 
[32] V.S. Farafonov, A.V. Lebed, N.O. Mchedlov-Petrossyan, Character of localization and microenvironment of the solvatochromic Reichardt's betaine dye in SDS and CTAB micelles: MD simulation study, Langmuir 33 (2017) 8342-8352, http://dx.doi.org/10.1021/acs.langmuir.7b01737

[33] V. S. Farafonov, A. V. Lebed, N. O. Mchedlov-Petrossyan Solvatochromic betaine dyes of different hydrophobicity in ionic surfactant micelles: Molecular dynamics modeling of location character. Colloids Surfaces A, 538 (2018) 583-592. https://doi.org/10.1016/j.colsurfa.2017.11.046

[34] V.S. Farafonov, A.V. Lebed, N.O. Mchedlov-Petrossyan, Examining solvatochromic Reichardt's dye in cationic micelles of different size via molecular dynamics, Issues of Chemistry and Chemical Technology 5 (2018) 62-68.

[35] G. Kortum, K.-W. Koch Die Dissoziationskonstante des 2,6-Dinitrophenols in Wasser-MethanolMischungen nach konduktometrischen und photometrischen Messungen, Ber. Bunsenges. Phys. Chem. 69 (1965) 677-683, https://doi.org/10.1002/bbpc.19650690806

[36] Indicators, ed. E. Bishop, Pergamon Press, Oxford, v.1, 1972.

[37] C. J. Drummond, F. Grieser, T. W. Healy, Acid-base equilibria in aqueous micellar solutions. Part 1. - 'Simple' weak acids and bases, J. Chem. Soc., Faraday Trans., 1, 85 (1989) 521-535. http://dx.doi.org/10.1039/F19898500521

[38] H.C. Hemker, Lipid solubility as a factor influencing the activity of uncoupling phenols, Biochim. Biophys. Acta 63 (1962) 46-54. https://doi.org/10.1016/0006-3002(62)90337-2

[39] F. Blaikie, S. Brown, L. Samuelsson, M.D. Brand, R. A. Smith, M.P. Murphy, Targeting Dinitrophenol to Mitochondria: Limitations to the Development of a Self-limiting Mitochondrial Protonophore, Biosci. Rep. 26 (2006) 231-243, http://dx.doi.org/10.1007/s10540-006-9018-8

[40] A.W. Ralston, A. Ingle, M.R. McCorkle, Observations on the effect of some solvents upon the acylation of phenol with high molecular weight acid chlorides, J. Org. Chem. 7 (1942) 457-461; http://dx.doi.org/10.1021/jo01200a001.

[41] B. Heinrich, D. Guillon, Tilt angle variation as a function of chain length and temperature in the smectic C phases of p,alkoxyphenyl-p, alkoxybenzoates, Mol. Cryst. Liq. Cryst., 268 (1995) 21-43; http://dx.doi.org/10.1080/10587259508030990.

[42] M.J. Abraham, T. Murtola, R. Schulz, S. Páll, J.C. Smith, B. Smith, E. Lindahl, GROMACS: High performance molecular simulations through multi-level parallelism from laptops to supercomputers, SoftwareX 1-2 (2015) 19-25, http://dx.doi.org/10.1016/j.softx.2015.06.001].

[43] M. Pisárčik, A. Devínsky, A. Pupák, Determination of micelle aggregation numbers of alkyltrimethylammonium bromide and sodium dodecyl sulfate surfactants using time-resolved fluorescence quenching, Open Chem. 13 (2015) 922-931, http://dx.doi.org/10.1515/chem-2015$\underline{0103 .}$. 
[44] W.L. Jorgensen, D.S. Maxwell, J. Tirado-Rives, Development and testing of the OPLS all-atom force field on conformational energetics and properties of organic liquids, J. Am. Chem. Soc. 118 (1996) 11225-11236, http://dx.doi.org/10.1021/ja9621760.

[45] V.S. Farafonov, A.V. Lebed, Developing and validating a set of all-atom potential models for sodium dodecyl sulfate, J. Chem. Theory Comput. 13 (2017) 2742-2750. http://dx.doi.org/10.1021/acs.jctc.7b00181

[46] V.S. Farafonov, A.V. Lebed, Molecular dynamics simulation study of cetylpyridinum chloride and cetyltrimethylammonium bromide micelles. Kharkov Univ. Bull., Chem. Ser. 27 (2016) 25-30. https://doi.org//10.26565/2220-637X-2017-27-03

[47] C.M. Breneman, K.B. Wiberg, Determining atom-centered monopoles from molecular electrostatic potentials. The need for high sampling density in formamide conformational analysis, J. Comp. Chem. 11 (1990) 361. http://dx.doi.org/10.1002/jcc.540110311

[48] E. Vanquelef, S. Simon, G. Marquant, E. Garcia, G. Klimerak, J. C. Delepine, P. Cieplak, F.-Y. Dupradeau, R.E.D. Server: a web service for deriving RESP and ESP charges and building force field libraries for new molecules and molecular fragments, Nucleic Acids Res 3, Suppl. 2 (2011) W511-W517. http://dx.doi.org/10.1093/nar/gkr288

[49] M.J. Frisch, G. W. Trucks, H.B. Schlegel, G.E. Scuseria, M.A. Robb, J.R. Cheeseman, G. Scalmani, V. Barone, B. Mennucci, G.A. Petersson, H. Nakatsuji, M. Caricato, X. Li, H.P. Hratchian, A.F. Izmaylov, J. Bloino, G. Zheng, J.L. Sonnenberg, M. Hada, M. Ehara, K. Toyota, R. Fukuda, J. Hasegawa, M. Ishida, T. Nakajima, Y. Honda, O. Kitao, H. Nakai, T. Vreven, J.A., Jr. Montgomery, J.E. Peralta, F. Ogliaro, M. Bearpark, J.J. Heyd, E. Brothers, K.N. Kudin, V.N. Staroverov, R. Kobayashi, J. Normand, K. Raghavachari, A. Rendell, J.C. Burant, S.S. Iyengar, J. Tomasi, M. Cossi, N. Rega, J.M. Millam, M. Klene, J.E. Knox, J.B. Cross, V. Bakken, C. Adamo, J. Jaramillo, R. Gomperts, R.E. Stratmann, O. Yazyev, A.J. Austin, R. Cammi, C. Pomelli, J.W. Ochterski, R.L. Martin, K. Morokuma, V.G. Zakrzewski, G.A. Voth, P. Salvador, J.J. Dannenberg, S. Dapprich, A. D. Daniels, Ö. Farkas, J.B. Foresman, J.V. Ortiz, J. Cioslowski, D.J. Fox, Gaussian 09, revision D.01. Gaussian, Inc.: Wallingford, CT., 2009.

[50] K. Seguchi, Effect of surfactants on the visible spectra and acidity of substituted nitriphenols, Yukugaku 28 (1979) 20-25.

[51] A. Mirgorodskaya, Y. Karpichev, E. Yackevich, I. Kapitanov, S. Lukashenko, L. Zakharova, A. Popov, A. Konovalov, Aggregation behavior and interface properties of mixed surfactant system gemini 14-s-14/CTABr. Colloids and Surfaces A: Physicochemical and Engineering Aspects, 457 (2014) 425-432, http://dx.doi.org/10.1016/j.colsurfa.2014.06.026

[52] A.G.Yakubovskaya, N.A. Vodolazkaya, N.O.Mchedlov-Petrossyan, Ionic equilibria of acid/base indicators in micellar media. Ionization of dinitrophenols in aqueous solutions of cationic and zwitterionic surfactants. Kharkov University Bull. Chem. Ser. (2006) issu 14, 217-229. 
[53] A.Goi, M. Trapido, Hydrogen peroxide photolysis, Fenton reagent and photo-Fenton for the degradation of nitrophenols: a comparative study, Chemosphere, 46 (2002), 913-922, http://dx.doi.org/10.1016/S0045-6535(01)00203-X

[54] C. J. Drummond, F. Grieser, Absorption spectra and acid-base dissociation of the 4-alkyl derivatives of 7-hydroxycoumarin in self-assembled surfactant solutions: Comments to their use as electrostatic surface potential probes. Photochem. Photobiol. 45 (1987) 19-34, http://dx.doi.org/10.1111/j.1751-1097.1987.tb08401.x

[55] H. Ohshima, T. W. Healy, L. R. White, Accurate analytic expressions for the surface charge density/surface potential relationship and double-layer potential distribution for a spherical colloidal particle, J. Coll. Int. Sci. 90 (1982) 17-26, https://doi.org/10.1016/0021-9797(82)90393-9

[56] P.A. Kralchevsky, K.D. Danov, N.D. Denkov, Chemical physics of colloid systems and interfaces. In: Handbook of Surface and Colloid Chemistry, K.S. Birdi (Ed.), CRC Press, Boca Raton, 2009, Ch. 7. 197-377.

[57] I. M. Kolthoff, M. K. Chantooni, S. Bhowmik, Dissociation constants of uncharged and monovalent cation acids in dimethyl sulfoxide, J. Amer. Chem. Soc. 90 (1968) 23-28. http://dx.doi.org/10.1021/ja01003a005

[58] K.-S. Stow, K.-P. Ang, Thermodynamics of ionization of 2,4- and 2,5-dinitrophenol in dimethylsulfoxide, Can. J. Chem. 58 (1980) 970-973. https://doi.org/10.1139/v80-153

[59] M. Hojo, M. Utaka, Z. Yoshida, Ortho effects-V: Ortho effects in the ionizations of benzoic acids in dimethyl sulfoxide-water mixed solvents, Tetrahedron, 27 (1971) 2713-2723, https://doi.org/10.1016/S0040-4020(01)98062-7 